\title{
Effects of saliva and nasal secretion on some physical properties of four different resin materials
}

\author{
Huseyin Kurtulmus ${ }^{1}$, Ovul Kumbuloglu ${ }^{1}$, Rahime Tuzunsoy Aktas ${ }^{1}$, Aylin Kurtulmus ${ }^{2}$, Hayal Boyacioglu ${ }^{3}$, \\ Onur Oral ${ }^{4}$, Atilla User ${ }^{1}$
}

${ }^{1}$ DDS, PhD, Ege University, Faculty of Dentistry, Department of Prosthodontics, 35100, Bornova, Izmir, Turkiye

${ }^{2} \mathrm{PhD}$, Ege University, Faculty of Pharmacy, Department of Pharmacognosy, 35100, Bornova, Izmir, Turkiye

${ }^{3} \mathrm{PhD}$, Ege University, Faculty of Science, Department of Statistics, 35100, Bornova, Izmir, Turkiye

${ }^{4}$ DDS, Ege University, Faculty of Dentistry, Department of Prosthodontics, 35100, Bornova, Izmir, Turkiye

Correspondence:

Ege University, Faculty of Dentistry

Department of Prosthodontics

35100, Bornova, Izmir, Turkiye

h_kurtulmus@yahoo.com

Received: $17 / 08 / 2009$

Accepted: $21 / 02 / 2010$

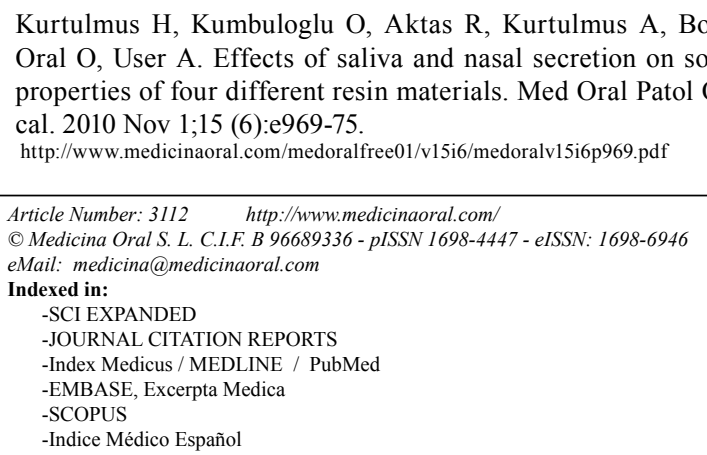

\begin{abstract}
Objective: Aim of this study was to evaluate possible effects of saliva and nasal secretion on some physical properties, such as sorption, solubility, surface hardness and colour change on four different resin-based materials over a certain time period.

Materials and Methods: A total of 128 disc-shaped specimens with a diameter of $50 \mathrm{~mm}$ and thickness of $0.5 \mathrm{~mm}$ were tested to evaluate sorption and solubility (ISO-1567). The specimens were stored in different solutions prior to testing. Surface hardness measurements were performed by using a Vickers hardness testing machine. A total of 20 cylindershaped test specimens with a diameter of $13 \mathrm{~mm}$ and thickness of $1 \mathrm{~mm}$ were prepared to evaluate colour change $(\Delta \mathrm{E})$. Analysis of variance was used to determine significant differences among groups. Paired $t$ and Tukey Post-Hoc tests were performed to investigate significant differences among subgroups at all time intervals $(\mathrm{p}<0.05)$.

Results: It was found that while the percentage absorption value at T7(7 days) of the auto-polymerizing (A) groups storaged in artificial saliva + nasal secretion were the highest $(0.057 \pm 0.119)$, the percentage absorption value at T15(15 days) of the $\mathrm{D}$ groups storaged in artificial nasal secretion were the lowest $(0.013 \pm 0.09)$. Besides, it was found that the percentage solubility value at T30(30 days) of visible ligth-cusing resin (VLC) groups storaged in artificial nasal secretion were the highest $(0.016 \pm 0.003)$, and the percentage solubility value at $\mathrm{T} 1(1$ day) of the $\mathrm{D}$ groups storaged in distilled water were the lowest $(0.01 \pm 0.02)$. While the highest hardness value was of T0(Dry) in group heat-polymerizing $(\mathrm{H})(36.19 \pm 1.35)$, the lowest hardness value was of $\mathrm{T} 0$ in group $\mathrm{D}(9.83 \pm 2.48)$. When $\triangle \mathrm{E}$ values analysed for each group, VLC group showed the highest values $(23.78 \pm 5.05)(\mathrm{p}<0.05)$, group $\mathrm{D}$ showed the lowest values $(9.06 \pm 2.82)$ in time (between the $\mathrm{T} 0$ and $\mathrm{T} 30$ ).

Conclusion: The new polyamide resin was observed to show better physical properties when compared with other materials.
\end{abstract}

Key words: Denture base, polymeric resin material, physical properties, solubility, sorption, hardness, colour change, artificial nasal secretion, artificial saliva. 


\section{Introduction}

Resin denture base materials have been widely used in fabrication of dental prostheses. Essential requirements for denture base polymers are adequate mechanical properties, sufficient aesthetics, easy handling of resin and minimal release of residual compounds (1). Heat-polymerized multiphase denture base polymer fills the requirement of good aesthetics quite well, when compared with auto-polymerized. Unfortunately, so far their poor physical properties have not totally been resolved (1-3). Although the properties of acrylic resin materials have been improved $(4,5)$, there are still disadvantages associated with their physical properties, chemical contents and polymerization methods. Problems such as loss of resilience, colour alterations, porosity (6) and dimensional change may occur in clinical use. In addition, the elution of residual monomers may lead to several side effects including soft tissue reactions on denture wearers. The loss of resiliency may be due to the leaching out of the plasticizer and other components. Simultaneously, water is absorbed until equilibrium is reached (7). Some new types of denture base resins are paste type (such as polyamide and plaque photo) of resins which are composed of monomers of a higher molecular weight than methyllmethacrylate (MMA) or oligomers. These monomers are trapped into the polymer structure and their release into water should be minor.

Many denture wearers fail to maintain a satisfactory level of hygiene (8),since increased porosity of resin materials may lead to plaque accumulation and Candida albicans colonization $(6,9)$. These disadvantages are associated with water sorption and solubility properties of acrylic resin polymers. Water sorption depends on the degree of hydrophobicity and porosity of the material (10). In clinical use, resin denture base materials are vulnerable to water sorption and solubility when immersed in an aqueous medium (11) such as saliva, nasal secretion, water or cleansing agents. When immersed in such solutions, plasticizers and other soluble compo- nents may leach out over extended periods (12-15) while water or saliva are being absorbed $(13,16)$. The loss of plasticizer may cause a decreased percentage of elongation and increased hardness values (17). Absorbed water has a detrimental effect on strength of resin denture base and physical and mechanical properties of the material $(13,17-20)$.

The aim of this study was to evaluate sorption, solubility, hardness value, colour alteration effects on four different resin denture base materials after artificial saliva and nasal secretion storage over time. The tested null hypotheses were that polyamide resin denture base material would result in better physical properties than other materials at both artificial saliva and nasal secretion.

\section{Materials and Methods}

An auto-polymerizing (group A), a heat-polymerizing denture base acrylic resin (group $\mathrm{H}$ ), a polyamide (group D) and a visible light-curing resin (group VLC) were prepared in accordance with directions of their manufacturers and used in this study (Table 1).

\section{Specimen Preparation}

Disc-shaped specimens (n:128) were prepared in accordance with International Standards Organization (ISO) specification $1567(10,11,13)$, and according to their manufacturer's instructions. Each specimen had a diameter of $50 \mathrm{~mm}$ and a thickness of $0.5 \mathrm{~mm}$. Thirtytwo circular specimens for each material were processed by using an acetate matrix measuring, and fabricated by using the curing cycles listed in (Table 1). The specimens were finished using progressively smoother aluminum oxide papers (numbers 320, 400, and 600). Final dimension of specimens after polishing has again been $50 \times 0.5 \mathrm{~mm}$. After processing, all disc-shaped specimens were dried with absorbent paper and allowed to stay at ambient temperature for 1 hour.

2. Weight Changes (Water sorption / solubility test)

Water sorption (Wsp) and solubility (Wsl) were deter-

Table 1. Denture base materials used in this study.

\begin{tabular}{|c|l|l|c|}
\hline Material & \multicolumn{1}{|c|}{ Manufacturer } & \multicolumn{1}{c|}{$\begin{array}{c}\text { Chemical composition \& Polymerization } \\
\text { cycle }\end{array}$} & $\begin{array}{c}\text { Batch } \\
\text { number }\end{array}$ \\
\hline $\begin{array}{c}\text { PMMA } \\
\text { (Denture base resin) }\end{array}$ & $\begin{array}{l}\text { Megadental, } \\
\text { Seeweg 20, } \\
\text { Büdingen, GERMANY }\end{array}$ & $\begin{array}{l}\text { Polymethylmethacrylate } \\
\text { Heat-polymerizing acrylic resin, 8h at } 70^{\circ} \mathrm{C} \\
\text { (dry heat). }\end{array}$ & D-63653 \\
\hline $\begin{array}{c}\text { PMMA } \\
\text { Penture base resin) }\end{array}$ & $\begin{array}{l}\text { Megadental, } \\
\text { Seeweg 20, Büdingen, } \\
\text { GERMANY }\end{array}$ & $\begin{array}{l}\text { Polymethylmethacrylate } \\
\text { Cold-cure (auto-polymerizing) acrylic resin, 20 } \\
\text { min at room temperature. }\end{array}$ & D-63654 \\
\hline $\begin{array}{c}\text { DEFLEX } \\
\text { (Denture base resin) }\end{array}$ & $\begin{array}{l}\text { Nuxen SRL, Ayacucho } \\
\text { 1053 3-A, Cap. Fed. } \\
\text { Buenos Aires, } \\
\text { ARGENTINA }\end{array}$ & $\begin{array}{l}\text { High-Impact Polyamide for dentures. } \\
\text { Pigmented thermoplastic polyamide, injection } \\
\text { at 6 bar pressure for 30 sec following } \\
\text { plasticization at 280 }{ }^{\circ} \text { C for 15 min. }\end{array}$ & 1228 \\
\hline $\begin{array}{l}\text { PLAQUE PHOTO } \\
\text { (Denture base resin) }\end{array}$ & $\begin{array}{l}\text { Barmstedt, Hamburg, } \\
\text { GERMANY }\end{array}$ & $\begin{array}{l}\text { Visible Light-curing acrylic resin base material } \\
\text { (VLC) (pink colour) }\end{array}$ & D-25355 \\
\hline
\end{tabular}


mined by using the method described by ISO, with the specification 1567:1997 (American Dental Association specification number 12) $(10,11)$.

Specimens were conditioned to constant mass in a desiccator (Terra Universal Inc., Fullerton, CA) at room temperature $\left(22-25 \mathrm{C}^{\circ}\right)$ until constant weight was reached. All specimens attained weight stability on an analytical scale by the 10th day. Because of this, each specimen was immediately weighed (T0) daily by use of an analytic balance (Sartorius, Goettingen, Germany) with an accuracy of $0.0001 \mathrm{~g}$ and subjected to a cycle as described below. Weight values obtained were considered as the initial weights of specimens $(\mathrm{m} 1)$. When specimens reached a constant mass, specimens of each material (group H, group A, group D and group VLC) were divided into four subgroups with 8 specimens and they were immersed and stored in artificial saliva (subgroup $\mathrm{S}$ ); consisting of $0.220 \mathrm{~g} / \mathrm{L}$ calcium chloride, $1.07 \mathrm{~g} / \mathrm{L}$ sodium phosphate, $1.68 \mathrm{~g} / \mathrm{L}$ sodium bicarbonate, and 2 $\mathrm{g} / \mathrm{L}$ sodium azide $0.2 \%(\mathrm{NaN} 3)(7)$; in artificial nasal secretion (subgroup $\mathrm{N}$ ); consisting of $\mathrm{Na}+107 \pm 4 \mathrm{mM}$, Cl- $120 \pm 6 \mathrm{mM}, \mathrm{K}+8,7 \pm 0,4 \mathrm{mM}$ according to in vivo microdialysis procedure (IVMD) (9); in co-solution (artificial saliva + artificial nasal secretion, subgroup $\mathrm{S}+\mathrm{N}$ ) and distilled water as control group (subgroup $\mathrm{W}$ ) at $37^{\circ} \mathrm{C} \pm 1{ }^{\circ} \mathrm{C}$ for 1 (twenty-four hours, $\mathrm{T} 1$ ), 7 (T7), 15 (T15) and 30 (T30) days. Nasal secretion was used to determine the effects on denture base materials in maxillofacial and postnasal flux patients.

After completing storage periods, 128 specimens were removed from these solutions and wiped with a clean dry towel or dried with absorbent paper, waved in air for $15 \mathrm{~s}$, and weighed (m2) $60 \mathrm{~s}$ after being removed from these solutions. Specimens were then re-conditioned to constant mass in a dessicator at the room temperature by using the same method previously described, their weights were verified again and recorded (m3) for the following time periods: immediately weighed (T0), 24 hours (T1), 7 days (T7), 15 days (T15), and 30 days (T30) after initial liquid storage. Artificial saliva and nasal secretion solutions were refreshed in a daily manner. They were measured and calculated as described below in units of micrograms $(\mu \mathrm{g})$. Weight differences between T0-T1, T1-T7, T7-T15, and T15-T30 were recorded. Percentages of water sorption and solubility were determined with described by Kazanji et al. (15) and El-Hadary et al. (14).

\section{Surface Hardness}

Surface micro hardness was determined using a Vickers hardness testing machine (Indentec, West Midlands, UK) according to American National Standards Institute / American Dental Association (ANSI / ADA) specification No. 17 (10). Two specimen discs, $22.8 \mathrm{~mm}$ in diameter and $1.5 \mathrm{~mm}$ in thickness were prepared for each material by using a circular stainless steel mould and were left in open environment at $25^{\circ} \mathrm{C}$ for 24 hours before testing. Testing was conducted using a load of $25 \mathrm{~g}$ with a 30 -second contact at T0 (Dry) and T30. Ten indentations were made on each specimen randomly along a straight line before they were immersed in solution and after they were stored in different artificial fluids. An average of 20 values obtained before and after the application was calculated for each specimen.

\section{Digital Measurements of Colour Change}

Colour changes were measured after immersion in solutions. Distilled water was used as negative control medium. A total of 20 cylinder-shaped specimens with a diameter of $13 \mathrm{~mm}$ and thickness of $1 \mathrm{~mm}$ were prepared with the help of split steel moulds. Testing procedure was performed on 4 different denture base materials in 2 separate sessions (T0-Dry, T30 for each artificial solution). In each session, all materials were placed on a white cardboard surface in order to get digital images (10). A white standard photograph paper was also used with the specimens as a calibration material to eliminate environmental factors. A digital camera (Olympus Camedia C-2500-L, Melville, NY, USA) at distance of $40 \mathrm{~cm}$ between the object and the camera was oriented perpendicularly towards specimens to capture the digital image. Images were taken at 11:00 am, under northern daylight on a clear day and saved in TIFF format (24-bit resolution screen) further analysis was assessed by the software (Adobe Photoshop 6.0, Adobe Systems Inc., San Jose, CA, USA). Colour measurements were performed according to the Commission Internationale del'Eclairage (CIE) [10] L*a*b* uniform colour scale. During the analyses, fixed circular areas with a diameter of 74 pixels were selected in the middle third portion of each specimen. Measurements were repeated 3 times for each specimen on a white background, and the mean values of $\mathrm{L}^{*}$ (brightness), a* (red-green proportion), and $b^{*}$ (yellow-blue proportion) were calculated. The 'corrected' $L^{*}, a^{*}, b^{*}$ values of each specimen were recorded as the baseline colour readings before immersion in solution (T0-Dry). Each specimen was immersed separately in vials for 30 days (T30). At the end of test period, specimens were removed and dried with tissue paper, and colour measurements were repeated. The post-treatment digital images of test specimens were obtained and analyzed to determine $L^{*}, a^{*}, b^{*}$ values of each specimen as mentioned previously. The total colour change and $\Delta \mathrm{E}$ of each test specimen were calculated using the equation (10).

Mean values and standard deviations (Sd) were calculated from the total colour change $(\Delta \mathrm{E}) . \Delta \mathrm{E}$ values equal to or less than 3.7 were considered to be visually imperceptible as well as clinically acceptable (10).

\section{Statistical Analysis}

Mean values and standard deviations were calculated for each group by using the Statistical Package for So- 
cial Sciences (SPSS) software, version 11.5 (SPSS Inc., Chicago, IL, USA). Differences in absorption and solubility for each material over time were analyzed for significance using Paired t test. Differences among various series of materials were analyzed for significance by using Univariate Analysis of Variance (ANOVA) and Tukey Post Hoc test with a significance level of $\mathrm{p}<0.05$.

\section{Results}

Differences among values of absorption groups for each day were not significant $(\mathrm{p}>0.05)$. Differences among solubility groups other than those at $\mathrm{T} 7$ were found to be statistically significant $(\mathrm{p}<0.05)$. It was found that solubility percentage value at T30 in group VLC stored in artificial nasal secretion was the highest $(0.016 \pm 0.003)$, where solubility percentage value at $\mathrm{T} 1$ in group $\mathrm{D}$ stored in distilled water was the lowest $(0.01 \pm 0.02)$. Change in value over time was found to be the highest in group VLC $(p<0.05)$ (Fig. 1).

The results showed that the highest mean hardness value was obtained at "T0 (Dry)" in group H (36.19 \pm 1.35 , Descriptive statistics), while the lowest hardness value was obtained at "T0 (Dry)" in group D $(9.83 \pm 0.022)$. Results of variance analysis showed that the difference among materials and solutions were statistically significant $(\mathrm{p}<0.05)$. All the materials tested had significantly different surface hardness values $(p<0.05)$. Only, differences between all solution groups in group $\mathrm{H}$ were found to be statistically significant $(\mathrm{p}<0.05)$ (Fig. 2).

$\triangle \mathrm{E}$ values for each group, group VLC showed the highest values $(23.78 \pm 5.05)$, while group D showed the lowest values $(9.06 \pm 2.82)$. Differences between groups were found to be statistically significant $(p<0.05)$. The differences between all groups excluding the difference between groups $\mathrm{A}$ and $\mathrm{H}$ were found to be statistically significant $(\mathrm{p}<0.05)$. It was found that differences between all groups excluding the difference between L1 and L2 values in group A were statistically significant $(\mathrm{p}<0.05)$ (Fig. 3a).

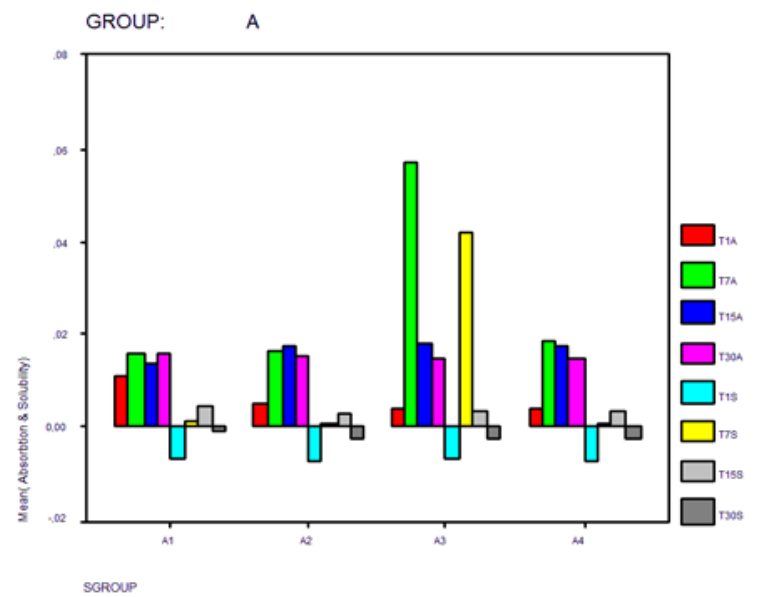

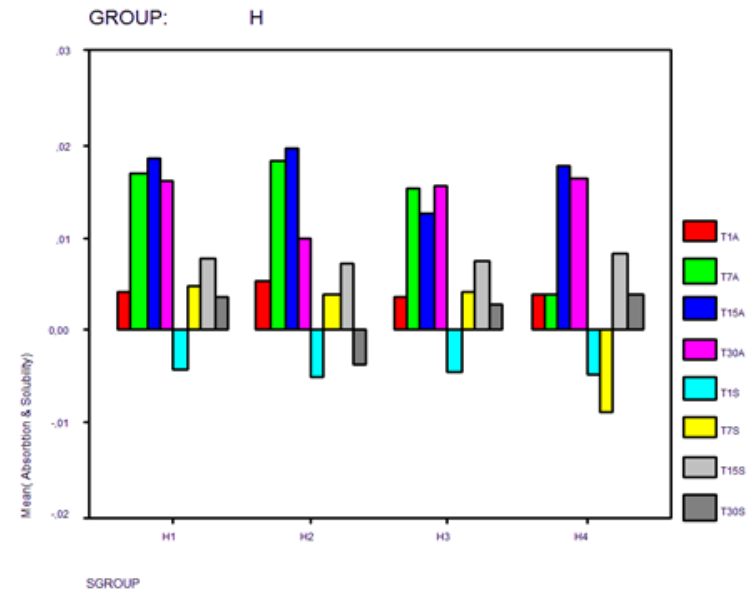

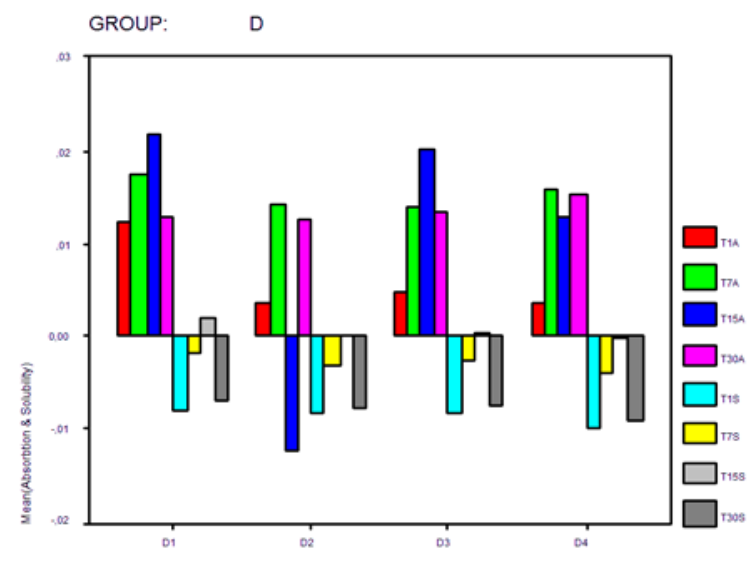

SGROUP

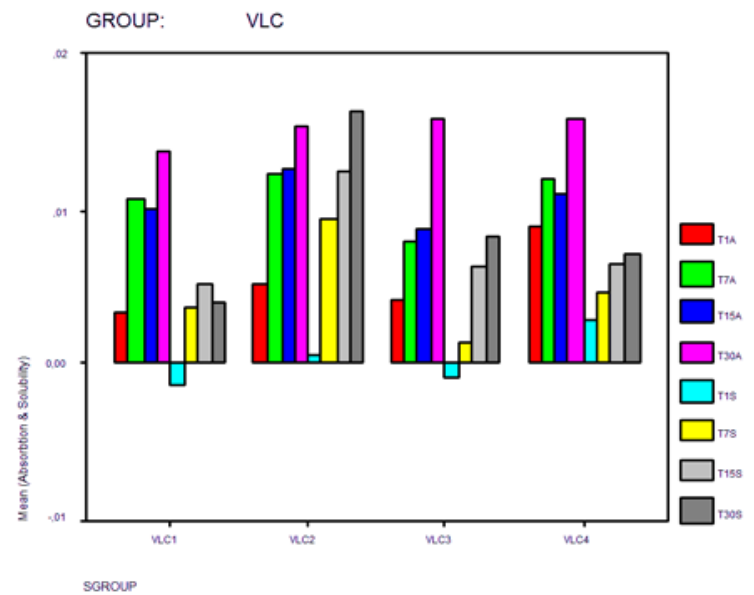

Fig. 1. Absorption, solubility values for Groups A, H, D, VLC which was exposed to four different liquids over time. 


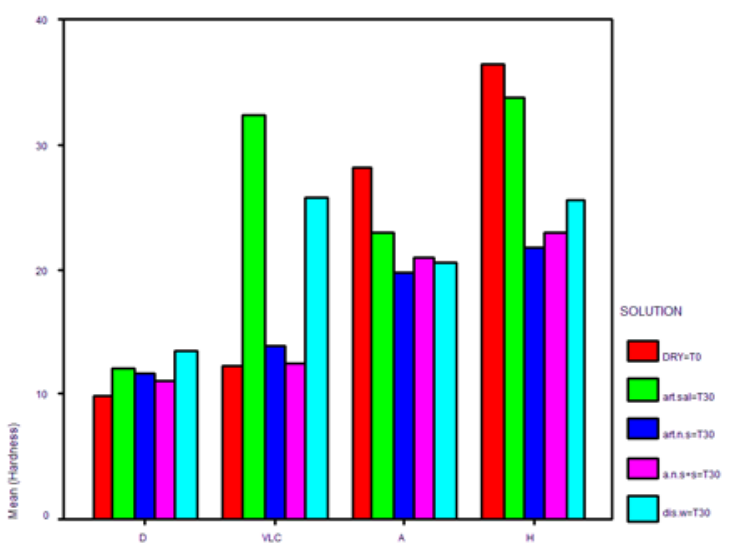

GRP

Fig. 2. Hardness values for each group (D, VLC, A, H) at initial (Dry: T0) and 30th day (T30) in four different storage solutions (art. sal: artificial saliva, art.n.s: artificial nasal secretion, a.n.s+s: artificial nasal secretion + saliva, dis.w: distilled water).
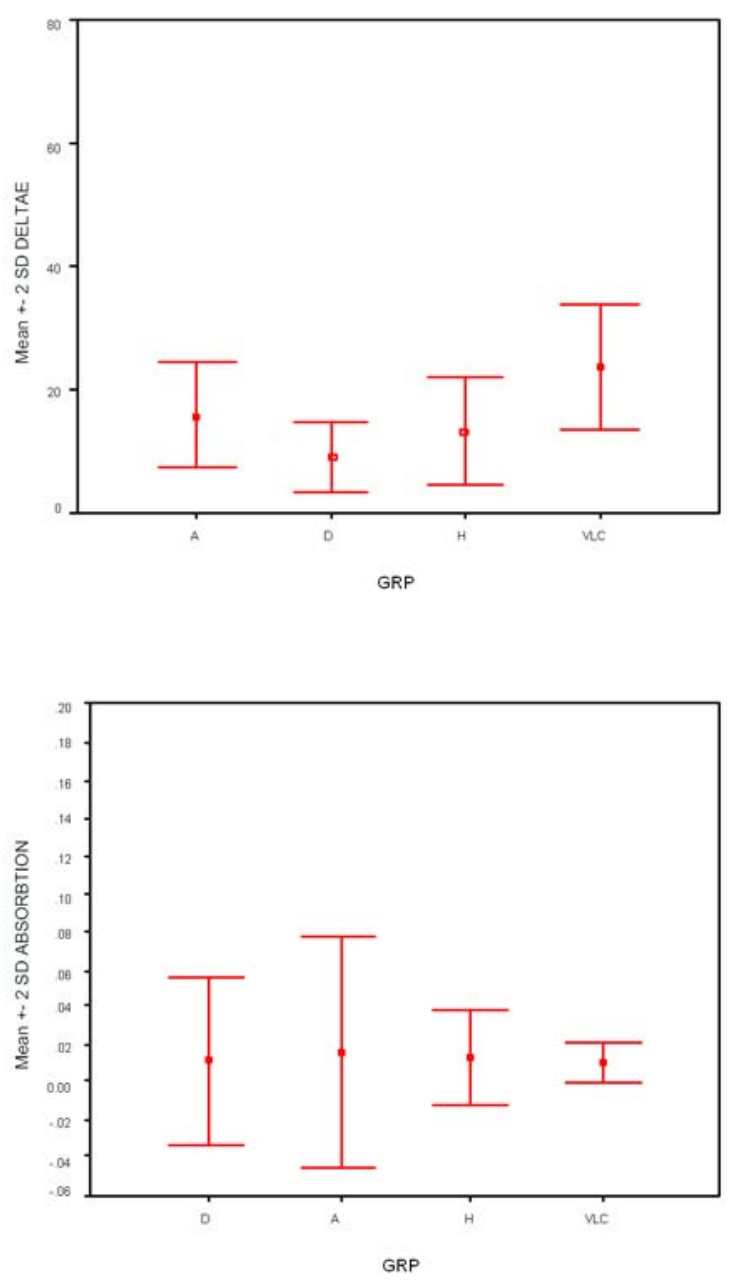
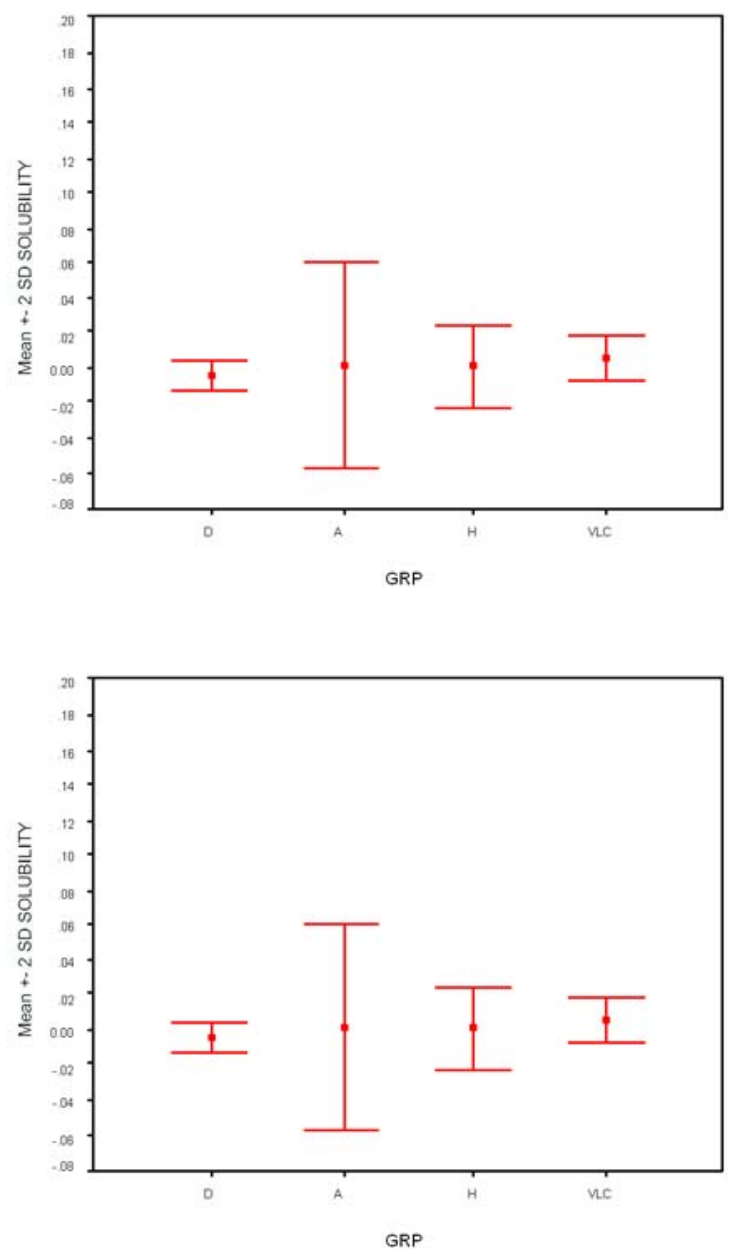

Fig. 3a,b,c,d. Error Bar Graph for each group: Results of Deflex compared with $\mathrm{A}, \mathrm{H}$ and $\mathrm{VLC}$ for $\triangle \mathrm{E}$ (colour change), sorption, solubility, surface hardness.

\section{Discussion}

Effects of saliva and nasal secretion in terms of sorption and solubility on denture base materials, processed by different methods, were evaluated.

While denture base materials are vulnerable to water sorption and solubility, they can absorb or loose soluble components in the liquids, depending on their composition and the solution in which they are immersed and this is the reason why the degradation occurs in materials $(5,11,15)$.

\section{Sorption}

Results showed no significant difference in mean values of liquid sorption among polymerization methods when all groups were evaluated for each day (11) (Fig. 3b).

The denture base material containing cross-linking agents absorbed fewer solutions than the materials without cross-linking agents $(10,20)$

\section{Solubility}

Solubility represents a loss of components during immersion, and eluted substances sometimes irritate denture-bearing tissue (10). 
Solubility values obtained in this study were lower than those reported by Cucci et al. (13) and showed significant difference in mean values of liquid sorption among resin materials when evaluated for each storage time (13).

In contrast to Cucci et al. (13), solubility values were from $1.0 \%$ to $1.6 \%$ which is in accordance with the values reported by El-Hadary et al. (14).

In this study, VLC showed a decreasing loss of mass mainly in artificial nasal secretion between T15 and T30. Polyamide showed a mass increase in distilled water after 1 day in spite of monomer leakage from the material. Polyamide specimens presented the lowest solubility value $(\mathrm{p}<0.05)$, when compared to other specimens.

Possible explanations for the increased mass of polyamide may be the polymerization method, chemical composition of the denture base material and the liquids, the presence of a cross-linking agent, chemical reactions with the solutions and concurrently, the amid monomer has lower liquid solubility than other monomers. This finding indicates that polyamide resin may cause less irritation to denture-bearing tissues when compared with other materials. This may have occurred because the degree of amid polymerization conversion was probably more complete with fewer residual components $(4,8,10-12,20)$ (Fig. 3c).

\section{Surface Hardness}

Group H dry values demonstrated significantly higher hardness values when compared to those in other materials tested. The research was harmonious with Smith et al. (5), and Parr and Rueggebergs' studies $(5,6)$. Hardness values for the group $\mathrm{H}$ product were consistently greater than those for the group A product and increased slightly over time. This result was consistent with that reported by Polyzois et al. (7) who also compared an autopolymerized and a heat-processed acrylic resin.

This result may be attributed to a high monomerpolymer ratio and attachment of this material and the presence of methylmethacrylate monomer. Moreover, cross-linking agents may exist in the material. Group D dry values demonstrated lower hardness values and also possessed lower amounts of cross-linking agents, indicating that cross-linking agent may affect surface hardness. This finding shows that polyamide resin is a more flexible material than the other materials tested (Fig. 3d).

\section{Colour Change}

The lowest degree of colour change (highest resistance to discoloration) observed in Group D, might be attributed to chemical structure and polymerization method of this material. It may potentially have a lower surface energy, resulting in the development of solutions-shedding qualities. VLC material showed the highest degree of colour change (lowest resistance to discoloration).
These results are in general agreement with the findings of Phoenix et al. (8) and Hayakawa et al. (10). Colour stability may depend on the chemical composition of the monomer $(4,10)$. Polyamide resin with its liquid shedding quality, may be expected to exhibit a high resistance to colour change in many varieties of oral environments (Fig 3a).

\section{Conclusion}

Resin based materials have been used to produce dentures. However, it has been forgotten that the quantity of saliva and nasal secretion absorbed by resin materials can make the appliance unhygienic.

\section{References}

1. Lassila LV, Vallittu PK. Denture base polymer Alldent Sinomer: mechanical properties, water sorption and release of residual compounds. J Oral Rehabil. 2001;28:607-13.

2. Oysaed H, Ruyter IE. Creep studies of multiphase acrylic systems. J Biomed Mater Res. 1989;23:719-33.

3. Buyukyilmaz S, Ruyter IE. Color stability of denture base polymers. Int J Prosthodont. 1994;7:372-82.

4. Arima T, Murata H, Hamada T. Analysis of composition and structure of hard autopolymerizing reline resins. J Oral Rehabil. 1996;23:346-52.

5. Smith LT, Powers JM, Ladd D. Mechanical properties of new denture resins polymerized by visible light, heat, and microwave energy. Int J Prosthodont. 1992;5:315-20.

6. Parr GR, Rueggeberg FA. In vitro hardness, water sorption, and resin solubility of laboratory-processed and autopolymerized longterm resilient denture liners over one year of water storage. J Prosthet Dent. 2002;88:139-44.

7. Polyzois GL, Frangou MJ. Influence of curing method, sealer, and water storage on the hardness of a soft lining material over time. J Prosthodont. 2001;10:42-5.

8. Phoenix RD, Mansueto MA, Ackerman NA, Jones RE. Evaluation of mechanical and thermal properties of commonly used denture base resins. J Prosthodont. 2004;13:17-27.

9. Grubb BR, Chadburn JL, Boucher RC. In vivo microdialysis for determination of nasal liquid ion composition. Am J Physiol Cell Physiol. 2002;282:C1423-31.

10. Hayakawa I, Akiba N, Keh E, Kasuga Y. Physical properties of a new denture lining material containing a fluoroalkyl methacrylate polymer. J Prosthet Dent. 2006;96:53-8.

11. León BL, Del Bel Cury AA, Rodrigues Garcia RC. Water sorption, solubility, and tensile bond strength of resilient denture lining materials polymerized by different methods after thermal cycling. J Prosthet Dent. 2005;93:282-7.

12. Arima T, Murata H, Hamada T. The effects of cross-linking agents on the water sorption and solubility characteristics of denture base resin. J Oral Rehabil. 1996;23:476-80.

13. Cucci AL, Vergani CE, Giampaolo ET, Afonso MC. Water sorption, solubility, and bond strength of two autopolymerizing acrylic resins and one heat-polymerizing acrylic resin. J Prosthet Dent. 1998;80:434-8.

14. El-Hadary A, Drummond JL. Comparative study of water sorption, solubility, and tensile bond strength of two soft lining materials. J Prosthet Dent. 2000;83:356-61.

15. Kazanji MN, Watkinson AC. Soft lining materials: their absorption of, and solubility in, artificial saliva. Br Dent J. 1988;165:91-4. 16. Braden M, Wright PS. Water absorption and water solubility of soft lining materials for acrylic dentures. J Dent Res. 1983;62:764-8. 17. Dootz ER, Koran A, Craig RG. Physical property comparison of 11 soft denture lining materials as a function of accelerated aging. J Prosthet Dent. 1993;69:114-9. 
18. Aydin AK, Terzioğlu H, Akinay AE, Ulubayram K, Hasirci N. Bond strength and failure analysis of lining materials to denture resin. Dent Mater. 1999;15:211-8.

19. Hekimoğlu C, Anil N. Sorption and solubility of soft denture liners after accelerated aging. Am J Dent. 1999;12:44-6.

20. Ortengren U, Wellendorf H, Karlsson S, Ruyter IE. Water sorption and solubility of dental composites and identification of monomers released in an aqueous environment. J Oral Rehabil. 2001;28:1106-15. 